\title{
Short Communication: \\ Identification of Mildew Locus $O(M L O)$ genes in Durio zibethinus genome corresponding with the Powdery Mildew disease
}

\author{
RAHMAT AZHARI KEMAL ${ }^{1,2 \vartheta}$, ERIC BERNARDUS L. SANDJAJA ${ }^{1}$, AUDI PUTRA SANTOSA ${ }^{1}$, \\ JEREMIAS IVAN ${ }^{3}$ \\ ${ }^{1}$ Department of BioTechnology, School of Life Sciences, Indonesia International Institute for Life Sciences. Jl. Pulomas Barat Kav. 88, East Jakarta \\ Jakarta, 13210, Indonesia \\ ${ }^{2}$ Department of Medical Biology, Faculty of Medicine, Universitas Riau. Jl. Diponegoro 1, Pekanbaru, Riau, 28133, Indonesia. Tel.: +62-761-839264, \\ "email: rahmat.azharikemal@lecturer.unri.ac.id \\ ${ }^{3}$ Department of BioInformatics, School of Life Sciences, Indonesia International Institute for Life Sciences. Jl. Pulomas Barat Kav. 88, East Jakarta, \\ Jakarta, 13210, Indonesia
}

Manuscript received: 4 March 2018. Revision accepted: 8 November 2018.

\begin{abstract}
Kemal RA, Sandjaja EBL, Santosa AP, Ivan J. 2018. Short Communication: Identification of Mildew Locus O (MLO) genes in Durio zibethinus genome corresponding with the Powdery Mildew disease. Biodiversitas 19: 2204-2212. Mildew Locus O (MLO) is a protein consisting of seven transmembrane domains and appears in the various type of plants. MLO proteins are classified into seven clades. It is known that specific clades have different roles in a plant. MLOs from Clades IV and V have been linked to plant's susceptibility to Powdery Mildew (PM) disease. This study aimed to provide an overview of $M L O$ genes present in durian (Durio zibethinus) genome. Bioinformatic analyses were conducted to analyze the phylogeny and structure of MLO genes and proteins in durian. The result showed that there were 20 putative $D z M L O$ genes in durian, encoding 39 putative DzMLO proteins. Durian MLOs belong to Clade I-VI with one protein belongs to Clade IV and five proteins belong to Clade V. Those six MLO proteins shared a common motif in C-terminal and second intracellular domains. Putative alternative splicing and differential expressions were observed among Clade V DzMLO genes. These findings will facilitate the functional characterization of MLO genes and proteins in durian. Functional studies, especially on Cterminal and second intracellular domains, need to be conducted to elucidate the role of MLO in PM susceptibility in durian.
\end{abstract}

Keywords: Bioinformatics, durian, Durio zibethinus, Mildew Locus O, powdery mildew

Abbreviations: CT: C-terminal, CaMBD: Calmodulin-binding domain, DzMLO: Durio zibethinus MLO, EC: Extracellular, IC: Intracellular, MLO: Mildew Locus O, NT: N-terminal, PM: Powdery Mildew, TM: Transmembrane

\section{INTRODUCTION}

Mildew Locus O (MLO) is a highly conserved protein containing seven transmembrane domains (Acevedo-Garcia et al. 2014; Rispail and Rubiales 2016). MLO proteins are classified into at least seven clades (Kusch et al. 2016) and members of clades IV and V have been linked to plant's susceptibility to Powdery Mildew (PM) disease (Appiano et al. 2015a). Powdery mildew is a plant disease caused by fungal infection from the order of Erysiphales (Kuhn et al. 2016). Fungal growth on the epidermal cells of the leaves can cover the leaves' surface area and lead to the declining photosynthesis rate (Heffer et al. 2006; Berg et al. 2017). The disease has been reported in some plants such as grapevines (Feechan et al. 2011), cherry (Hubert et al. 2012), and legumes (Rubiales et al. 2015).

MLO has also been reported to have another role in phytohormones signaling, stress response processes, and root thigmomorphogenesis (Chen et al. 2009; AcevedoGarcia et al. 2014). Some reports suggested that knockout of $M L O$ gene should be performed to prevent the Powdery Mildew diseases (Pessina et al. 2016), but there are possibilities that the disruption or knockout of $M L O$ genes may hamper the regulation or process of phytohormones and stress responses. However, the biochemical function of MLO proteins remains unknown (Kusch et al. 2016; Zheng et al. 2016). Therefore, functional study of MLO proteins becomes interesting. To study them, the first step is to identify $M L O$ genes.

Analysis of $M L O$ gene can be conducted by cloning and characterization of a single gene (Cheng et al. 2012; Cheng et al. 2013; Qin et al. 2015). Currently there are some reports analyzing $M L O$ genes on the whole genome level, for example in cucumber (Zhou et al. 2013; Schouten et al. 2014), rose (Qiu et al. 2015), pea (Mohapatra et al. 2016), legumes (Rispail and Rubiales 2016), sweet orange (Liu et al. 2017), barrel clover, and chickpea (Deshmukh et al. 2017). Durian (Durio zibethinus) is a native fruit to SouthEast Asia region which draft genome was recently published (Teh et al. 2017). This fruit has been known for its sweet taste with a strong penetrating odor, and this fruit is deeply appreciated in South-East Asia as the 'king of fruit' (Li et al. 2012). There is a report that Durio zibethinus can act as a host of Powdery Mildew diseases (AQIS 1999; Siahaan et al. 2016) which might be correlated with the activity of $M L O$ genes. This study 
aimed to analyze the number, structure, and pattern of $M L O$ gene family in durian genome. Results from this analysis are expected to provide insight on further functional studies of the $M L O$ genes in durian.

\section{MATERIALS AND METHODS}

\section{Retrieval of putative $M L O$ genes from Durio zibethinus}

The genome of Durio zibethinus was retrieved from NCBI (Genome ID: 57226). Using Genome BLAST tool, a blast was conducted on the genome using Arabidopsis thaliana MLO 2 (AtMLO2) protein sequence. Protein and its corresponding gene and mRNA sequences were downloaded for these analyses. Retrieved proteins were checked for the presence of MLO domain using Pfam (http://pfam.xfam.org/). Sequences without MLO domain were omitted. Gene and mRNA sequences were checked for the locus and mRNA products in NCBI. Locus of the respective gene was obtained from the GeneID site, while the mRNA product was obtained from the CDS in the GenBank. Proteins from the same gene locus but resulted from different mRNA were grouped as putative isoforms. mRNA coding for miscellaneous mRNA was omitted from the analysis. Information on coding region length, number of exon and intron, and amino acid residues were recorded. Proteins were analyzed for putative molecular weight and isoelectric point using ExPASy (https://web.expasy.org/compute_pi/). $\square$

\section{Protein phylogenetic analysis}

The longest isoform of each durian MLO (DzMLO) protein was selected for phylogenetic analysis. For comparison and clade determination, MLO protein sequences from other dicots were retrieved from the NCBI database. These were of $A$. thaliana (AtMLO1-AtMLO15), Aquilegia coerulea (AcMLO1, AcMLO3, AcMLO4, AcMLO5, AcMLO9, AcMLO10, AcMLO12, AcMLO13), Fragaria vesca (FvMLO1, FvMLO7, FvMLO9, FvMLO10, FvMLO13, FvMLO14, FvMLO17), Glycine max (GmMLO4, GmMLO7, GmMLO8, GmMLO24, GmMLO28, GmMLO30, GmMLO31, GmMLO33), Nelumbo nucifera (NnMLO1, NnMLO5, NnMLO3, NnMLO6, NnMLO8, NnMLO11, NnMLO12, NnMLO13). MLO protein sequences were also retrieved from monocots Hordeum vulgare (HvMLO1, HvMLO2, HvMLO7, HvMLO8), Oryza sativa (OsMLO3, OsMLO4, OsMLO8, OsMLO12), Triticum aestivum (TaMLO B1, TaMLO4, TaMLO5, TaMLO6), Zea mays (ZmMLO1, ZmMLO2, ZmMLO11, ZmMLO13). Multiple sequence alignment (MSA) of MLO protein sequences was conducted using MUSCLE (Edgar 2004), and Maximum Likelihood phylogenetic tree was constructed with 1000 times bootstrap replicates (Hall 2013).

\section{Phylogenetic and structure analysis and $D z M L O$ genes}

$D z M L O$ genes were aligned using CLUSTALW, and the phylogenetic tree was constructed by MEGA 5 (Tamura et al. 2011) using Maximum Likelihood method with Tamura-Nei model (Tamura and Nei 1993) and 1000 times bootstrap (Hall 2013). Branches supported with less than 50 bootstrap value were collapsed. The resulting tree was exported as Newick file, and the gene structure was drawn with Gene Structure Display Server 2.0 (GSDS 2.0: http://gsds.cbi.pku.edu.cn/). $\square$

\section{Protein motif and gene ontology prediction}

To enable motif comparison within and between clades, all 39 putative DzMLO proteins were aligned using CLUSTALW, and the phylogenetic tree was constructed by MEGA 5 (Tamura et al. 2011) using Maximum Likelihood method JTT matrix-based model (Jones et al. 1992) and 1000 times bootstrap replicates (Hall 2013). Branches supported with less than $50 \%$ bootstrap value were collapsed. Conserved motifs in amino acid sequences were analyzed using the MEME algorithm (Bailey et al. 2009). The parameters were set to search a maximum of 20 motifs with 25-50 residues wide. Several identified motifs were analyzed using FIMO search tool (Grant et al. 2011) against the Ensembl Genomes database for Saccharomyces cerevisiae version 86 . Gene list obtained was analyzed using Generic GO Term Finder (Boyle et al. 2004) and annotated using Saccharomyces cerevisiae SGD for processing ontological aspect.

\section{Expression pattern analysis}

mRNA sequences belonged to Clades IV, and V were analyzed using BLAST in Sequence Read Archive (SRA) database. The RNA's sequences of Durio zibethinus Musang King isolated from leaf, root, stem, and arils were obtained by Teh et al. (2017) served as a template. Putative expression pattern was obtained based on the coverage of the sequence. Sequences that are covered by the short reads with less than $200 \mathrm{bp}$ gaps are coded as expressed $(+) . \square$

\section{RESULTS AND DISCUSSION}

\section{Identification of durian $M L O(D z M L O)$ gene family}

Analysis showed that there are 20 putative $M L O$ genes in durian genome (Table 1). This number is in line with other eudicot members that have 13-39 genes with a mean of $19.5 \mathrm{MLO} / \mathrm{species}$ (Kusch et al. 2016). MLO gene structure such as number of predicted introns that seems to be relatively conserved even among phylogenetically distant plant species such as potato Solanum tuberosum (Appiano et al. 2015b), tomato S. lycopersium (Zheng et al. 2016), thale cress $A$. thaliana, barley $H$. vulgare, rice $O$. sativa (Devoto 2003), barrel clover Medicago truncatula, and chickpea Cicer arietinum (Deshmukh et al. 2017). Eight $(40 \%)$ genes are predicted to code for isoform proteins. Four genes (DzMLO4, DzMLO13, DzMLO15, $D z M L O 17)$ produce two isoforms, two genes (DzMLO3, $D z M L O 19)$ produce three isoforms, one gene (DzMLO16) produces five isoforms, and one gene (DzMLO18) produces eight isoforms. Therefore, it is predicted that durian has 39 MLO proteins. The predicted molecular weight ranges from $38.99 \mathrm{kDa}$ (DzMLO18 X8) to $67.14 \mathrm{kDa}$ (DzMLO12). All proteins are predicted to be alkaline (Table 1) which is similar to all predicted MLO proteins such as those from S. lycopersicum (Chen et al. 2014), $M$. truncatula, and C. arietinum (Deshmukh et al. 2017). 
Table 1. Putative $M L O$ genes from $D$. zibethinus and their corresponding products

\begin{tabular}{|c|c|c|c|c|c|c|c|c|c|}
\hline Name & Gene & Isoform & $\begin{array}{l}\text { Coding } \\
\text { region } \\
\text { (bp) }\end{array}$ & $\begin{array}{l}\text { Exon } \\
\text { number }\end{array}$ & $\begin{array}{l}\text { Intron } \\
\text { number }\end{array}$ & $\begin{array}{l}\text { Amino acid } \\
\text { residues }\end{array}$ & $\begin{array}{l}\text { Protein } \\
\text { Accession } \\
\text { Number } \\
\end{array}$ & $\begin{array}{l}\text { The molecular } \\
\text { weight (kDa) }\end{array}$ & $\begin{array}{l}\text { Isoelectric } \\
\text { point }\end{array}$ \\
\hline DzMLO1 & LOC111315043 & & 1470 & 14 & 13 & 489 & XP_022772397.1 & 56.13 & 9.23 \\
\hline DzMLO2 & LOC111294434 & & 1515 & 13 & 12 & 504 & XP 022743467.1 & 57.15 & 8.95 \\
\hline \multirow[t]{3}{*}{ DzMLO3 } & LOC111277785 & $\mathrm{X} 1$ & 1509 & 13 & 12 & 502 & XP_022719935.1 & 56.99 & 8.86 \\
\hline & & $\mathrm{X} 2$ & 1434 & 12 & 11 & 477 & XP_022719936.1 & 54.02 & 8.69 \\
\hline & & $\mathrm{X} 3$ & 1320 & 12 & 11 & 439 & XP_022719937.1 & 50.18 & 8.85 \\
\hline \multirow[t]{2}{*}{ DzMLO4 } & LOC111276721 & $\mathrm{X} 1$ & 1509 & 14 & 13 & 502 & XP_022718216.1 & 57.68 & 8.43 \\
\hline & & $\mathrm{X} 2$ & 1506 & 14 & 13 & 501 & XP 022718217.1 & 57.61 & 8.43 \\
\hline DzMLO5 & LOC111310601 & & 1359 & 13 & 12 & 452 & XP_022765807.1 & 51.84 & 7.66 \\
\hline DzMLO6 & LOC111304402 & & 1590 & 15 & 14 & 529 & XP_022756687.1 & 60.08 & 9.09 \\
\hline DzMLO7 & LOC111300107 & & 1677 & 15 & 14 & 558 & XP_022751467.1 & 64.66 & 8.82 \\
\hline DzMLO8 & LOC111296618 & & 1704 & 15 & 14 & 567 & XP_022746752.1 & 65.03 & 8.81 \\
\hline DzMLO9 & LOC111292305 & & 1707 & 15 & 14 & 568 & XP_022740337.1 & 65.76 & 8.29 \\
\hline DzMLO10 & LOC111310303 & & 1713 & 15 & 14 & 570 & XP_022765350.1 & 66.16 & 9.31 \\
\hline DzMLO11 & LOC111304404 & & 1716 & 15 & 14 & 571 & $\mathrm{XP}^{-} 022756688.1$ & 66.28 & 9.64 \\
\hline DzMLO12 & LOC111284736 & & 1746 & 15 & 14 & 581 & XP-022729353.1 & 67.14 & 8.03 \\
\hline \multirow{2}{*}{ DzMLO13 } & LOC111311041 & $\mathrm{X} 1$ & 1680 & 15 & 14 & 559 & XP_022766152.1 & 64.52 & 9.37 \\
\hline & & $\mathrm{X} 2$ & 1674 & 15 & 14 & 557 & XP_022766153.1 & 64.23 & 9.42 \\
\hline DzMLO14 & LOC111310872 & & 1563 & 15 & 14 & 520 & XP_022765985.1 & 58.91 & 9.15 \\
\hline \multirow{3}{*}{ DzMLO15 } & LOC111292943 & $\mathrm{X} 1$ & 1713 & 15 & 14 & 570 & $\mathrm{XP}^{-} 022741334.1$ & 65.15 & 9.37 \\
\hline & & $\mathrm{X} 2$ & 1338 & 14 & 13 & 445 & & 51.37 & 9.47 \\
\hline & & & & & & & (XP 022741335.1 & & \\
\hline \multirow[t]{5}{*}{ DzMLO16 } & LOC111301676 & $\mathrm{X} 1$ & 1704 & 15 & 14 & 567 & XP_022753242.1 & 65.23 & 8.68 \\
\hline & & $\mathrm{X} 2$ & 1701 & 15 & 14 & 566 & XP_022753243.1 & 65.10 & 8.68 \\
\hline & & X3 & 1668 & 14 & 13 & 555 & XP_022753244.1 & 63.68 & 8.80 \\
\hline & & $\mathrm{X} 4$ & 1587 & 14 & 13 & 528 & $\mathrm{XP}^{-} 022753245.1$ & 60.76 & 8.87 \\
\hline & & $\mathrm{X} 5$ & 1494 & 12 & 11 & 497 & XP_022753246.1 & 56.83 & 8.14 \\
\hline \multirow[t]{2}{*}{ DzMLO17 } & LOC111296812 & $\mathrm{X} 1$ & 1695 & 15 & 14 & 564 & $\mathrm{XP} 022747015.1$ & 64.89 & 9.20 \\
\hline & & $\mathrm{X} 2$ & 1287 & 14 & 13 & 428 & $\mathrm{XP}^{-} 022747016.1$ & 49.50 & 9.21 \\
\hline \multirow[t]{8}{*}{ DzMLO18 } & LOC111284848 & $\mathrm{X} 1$ & 1392 & 13 & 12 & 463 & XP_022729613.1 & 53.54 & 8.60 \\
\hline & & $\mathrm{X} 2$ & 1296 & 14 & 13 & 431 & XP_022729615.1 & 49.87 & 8.61 \\
\hline & & X3 & 1215 & 11 & 10 & 404 & XP_022729617.1 & 46.94 & 8.56 \\
\hline & & $\mathrm{X} 4$ & 1182 & 12 & 11 & 393 & $\mathrm{XP}^{-} 022729619.1$ & 45.70 & 8.78 \\
\hline & & X5 & 1182 & 12 & 11 & 393 & XP-022729620.1 & 45.00 & 8.75 \\
\hline & & X6 & 1119 & 11 & 10 & 372 & XP 022729621.1 & 43.22 & 8.68 \\
\hline & & $\mathrm{X} 7$ & 1053 & 10 & 9 & 350 & XP_022729622.1 & 40.16 & 8.65 \\
\hline & & $\mathrm{X} 8$ & 1002 & 10 & 9 & 333 & XP_022729623.1 & 38.99 & 8.91 \\
\hline \multirow[t]{3}{*}{ DzMLO19 } & LOC111275322 & $\mathrm{X} 1$ & 1461 & 14 & 13 & 486 & $\mathrm{XP}^{-} 022716339.1$ & 56.84 & 8.70 \\
\hline & & $\mathrm{X} 2$ & 1344 & 13 & 12 & 447 & $\mathrm{XP}^{-} 022716340.1$ & 52.62 & 8.62 \\
\hline & & $\mathrm{X} 3$ & 1191 & 13 & 12 & 396 & $\mathrm{XP}-022716341.1$ & 46.16 & 8.81 \\
\hline DzMLO20 & LOC111312931 & - & 1692 & 14 & 13 & 563 & XP 022769423.1 & 64.27 & 9.27 \\
\hline
\end{tabular}

Table 2. Clades classification of $D z M L O$

\begin{tabular}{llc}
\hline Clade & DzMLO & Amount (\%) \\
\hline I & $7,8,9,16$ & $4(20 \%)$ \\
II & $1,2,3,4,18,19$ & $6(30 \%)$ \\
III & 14,15 & $2(10 \%)$ \\
IV & 20 & $1(5 \%)$ \\
V & $10,11,12,13,17$ & $5(25 \%)$ \\
VI & 5,6 & $2(10 \%)$ \\
VII & - & $0(0 \%)$ \\
\hline
\end{tabular}

\section{Phylogenetic of durian MLO (DzMLO) protein}

The result of phylogenetic analysis of durian MLO protein family showed separation of MLOs into several clades (Figure 1). Clades numbering was based on Arabidopsis MLO protein classification (Devoto et al.
2003, Appiano et al. 2015b) (Figure 1). The results showed that MLO proteins from durian belong to Clades I-VI (Table 2). Majority of durian MLO (6 of 20, 30\%) are members of Clade II. The clade distribution resembles other dicots (Kusch et al. 2016).

\section{$M L O$ gene structure analysis}

The number of exons in $D z M L O$ genes ranges from 10 to 15 , while the number of introns ranges from 9 to 14 . The majority $(60 \%)$ of the longest isoform genes have 15 exons and 14 introns (Table 1). Gene structure analysis (Figure 2) showed the differences in gene structure between $D z M L O$ genes. The phylogenetic tree and gene structure support the presence of $20 M L O$ genes. The grouping of $D z M L O$ genes supports the classification of DzMLO protein family in Figure 1. Some possible types of alternative splicing 
occurred are exon skipping, intron retention, alternative promoter, and alternative polyadenylation sites (Black 2003, Keren et al. 2010). In an exon-skipping mechanism, an exon can be regulated to be excluded in the mature mRNA. The fourth exon of DzMLO19 might be an example of this mechanism. The inclusion of the exon results in the longest $\mathrm{X} 1$ isoform, while exon skipping results in shorter $\mathrm{X} 2$ isoform. An intron can be retained in the mature mRNA; as in DzMLO18 X1 and X2 isoforms which difference might have resulted from intron retention. The intron between the ninth and tenth exons of DzMLO18 $X 2$ might be retained to produce longer ninth exon of $D z M L O 18 X 1$. Alternative promoters can result in different transcription start, therefore different 5'-end exon. Difference between $D z M L O 18 \mathrm{X} 1$ and $\mathrm{X} 3$ isoforms might be produced by different promoter use, making $D z M L O 18$ $\mathrm{X} 3$ isoform has longer untranslated upstream and lacks the first two exons of DzMLO18 X1. Alternative polyadenylation site can result in different transcription termination, therefore different 3'-end exon. Difference between $D z M L O 17 \mathrm{X} 1$ and X2 isoforms might be produced by the use of different polyadenylation site, making $D z M L O 17 \mathrm{X} 2$ isoform has longer untranslated downstream and lacks the last exon of $D z M L O 17 \mathrm{X} 1$. Two members of Clade V MLO, DzMLO13 and DzMLO17, are suggested to undergo alternative splicing. Alternative splicing of MLO genes has also been observed in tomato (Zheng et al. 2016). Data mining on Plant Alternative Splicing Database (http://proteomics.ysu.edu/altsplice/) also showed the presence of alternative splicing in several Clade $\mathrm{V} M L O$, such as Nelumbo nucifera NnMLO7 and Malus domestica MdMLO19, as well as Clade IV MLO Zea mays ZmMLO1.

\section{MLO protein motif}

Most conserved MLO protein motifs (Motifs 1-5, 7-8) are located in transmembrane (TM) and intracellular (IC) domains (Figure 3). When DzMLO proteins were analyzed using only one longest isoform for each gene, a motif that contains a calmodulin-binding domain (CaMBD) was found in all DzMLO except DzMLO18 (data not shown). When all putative MLO was analyzed, a motif that contains CaMBD (Motif 9) was detected in all DzMLO including DzMLO18 (Figure 3). CaMBD in DzMLO18 is located in the second intracellular domain (IC2), but in other DzMLOs, it is located in C-terminal (CT). $\square$

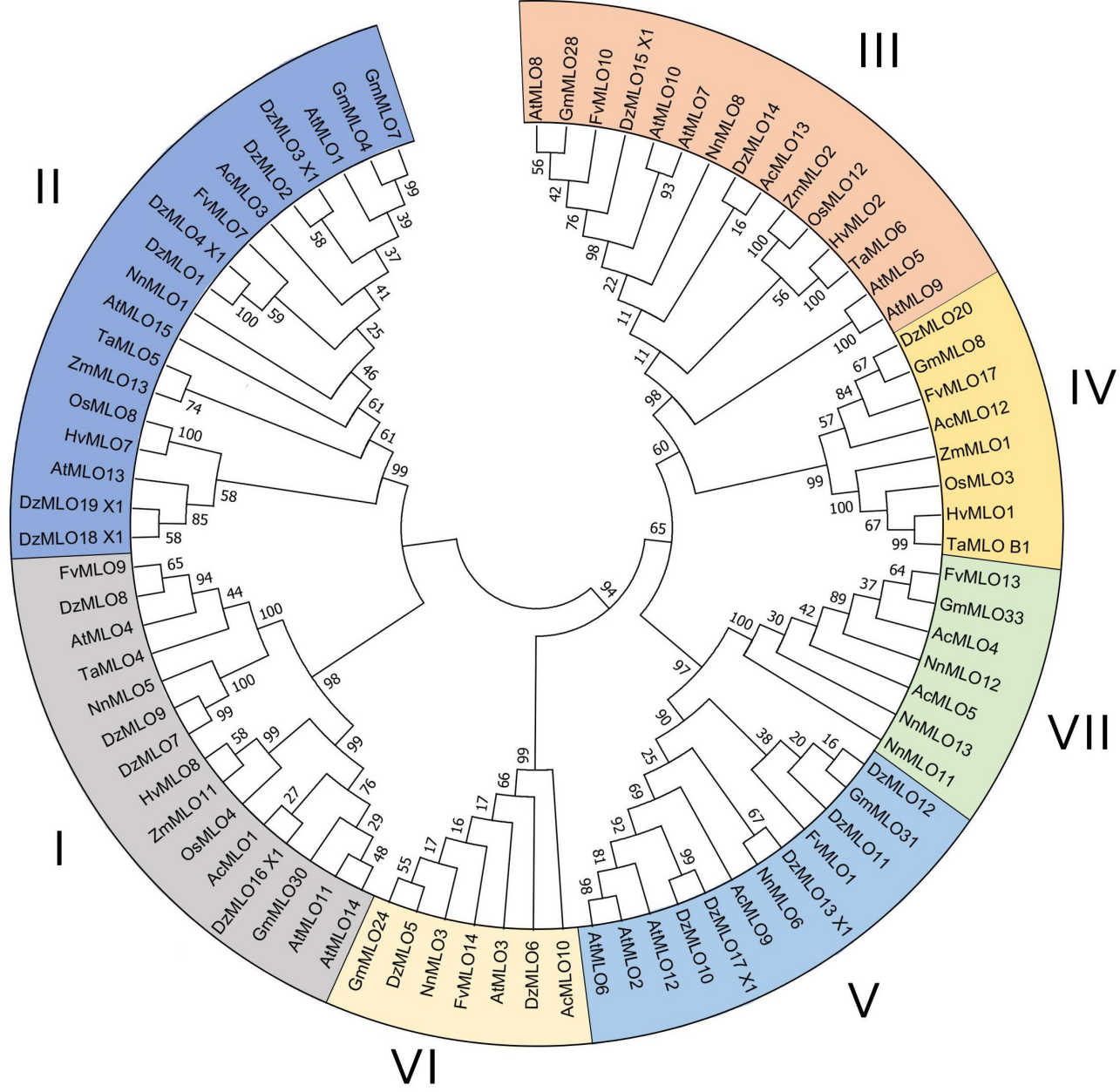

Figure 1. Phylogenetic tree of MLO protein from durian and other angiosperms showed seven clades. Members of durian MLO were distributed in all clades except for Clade VII. The number on the branches indicates the percentage of 1000 bootstrap replicates that support the node. The tree was constructed using MEGA 5 software (Tamura et al. 2011) 


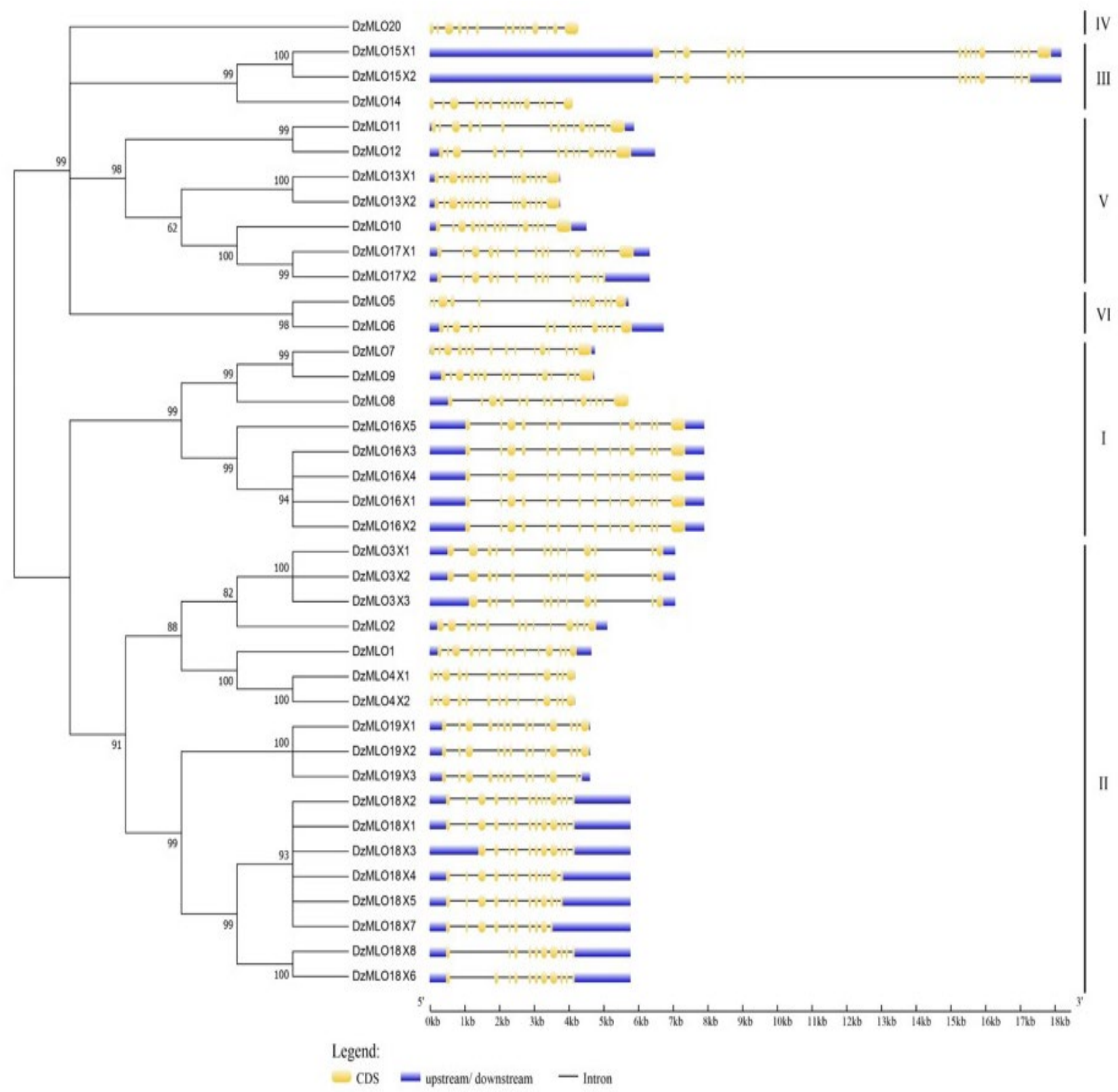

Figure 2. Phylogenetic tree and structure of $D z M L O$ genes. There were variations among genes and similarity among isoforms in term of number, position, and length of exon, intron, and upstream/downstream regions. Gene structure was constructed using GSDS 2.0, and the accompanying dendogram was constructed using MEGA 5 (Tamura et al. 2011)

Other variable motifs showed association with clades (Table 3). A motif in IC2 is different between DzMLO Clade I and other clades. Motif 13 is only detected in Clade I but seems to be replaced by Motif 6 in other clades. Motifs 6 and 10 are found in DzMLO Clades II-VI while Motif 20 is only found in Clades III-VI. Motif 17 is found in first extracellular (EC1) domain of Clades IV and V as well as in CT of two members of Clade I (DzMLO9 and DzMLO16). Motif 15 is only found in C-terminal of Clades IV and V. Two members of Clade V, DzMLO 13 and DzMLO17, are predicted to undergo alternative splicing.
Both DzMLO13 isoforms have identical motif organization. However, isoform 2 of DzMLO17 lacks motifs 9 and 15 which contain CaMBD motif and Cterminal respectively (Figure 3). Clade-specific motif diversification was also observed by Kusch et al. (2016).

Protein motifs supported the gene structure analysis. Motif variations between isoforms suggested the alternative splicing events. Analysis of three isoforms DzMLO3 can serve as an example. Gene structure difference between $D z M L O 3 \times \mathrm{X} 1$ dan $\mathrm{X} 2$ is the lack of the sixth exon in $D z M L O 3 \times 2$ (Figure 2). This is supported by the lack of 
the sixth motif, containing Motif 6, in DzMLO3 X2 protein (Figure 3). Gene structure difference between DzMLO3 X1 dan $\mathrm{X} 3$ is the longer untranslated upstream region in DzMLO3 X3 (Figure 2). This is supported by the lack of first two motifs, containing Motifs 3 and 8, in DzMLO3 X3 protein (Figure 3).

Motifs found in Clades IV and V predict the function of the protein in molecule transport and cellular process regulation (Table 3). This functional assignment was also predicted by Kusch et al. (2016). The Saccharomyces cerevisiae is distantly related to plants and lacks MLO proteins. However, it has one of the best-annotated genomes, therefore enabling detailed and comprehensive gene ontology analysis (Kusch et al. 2016).

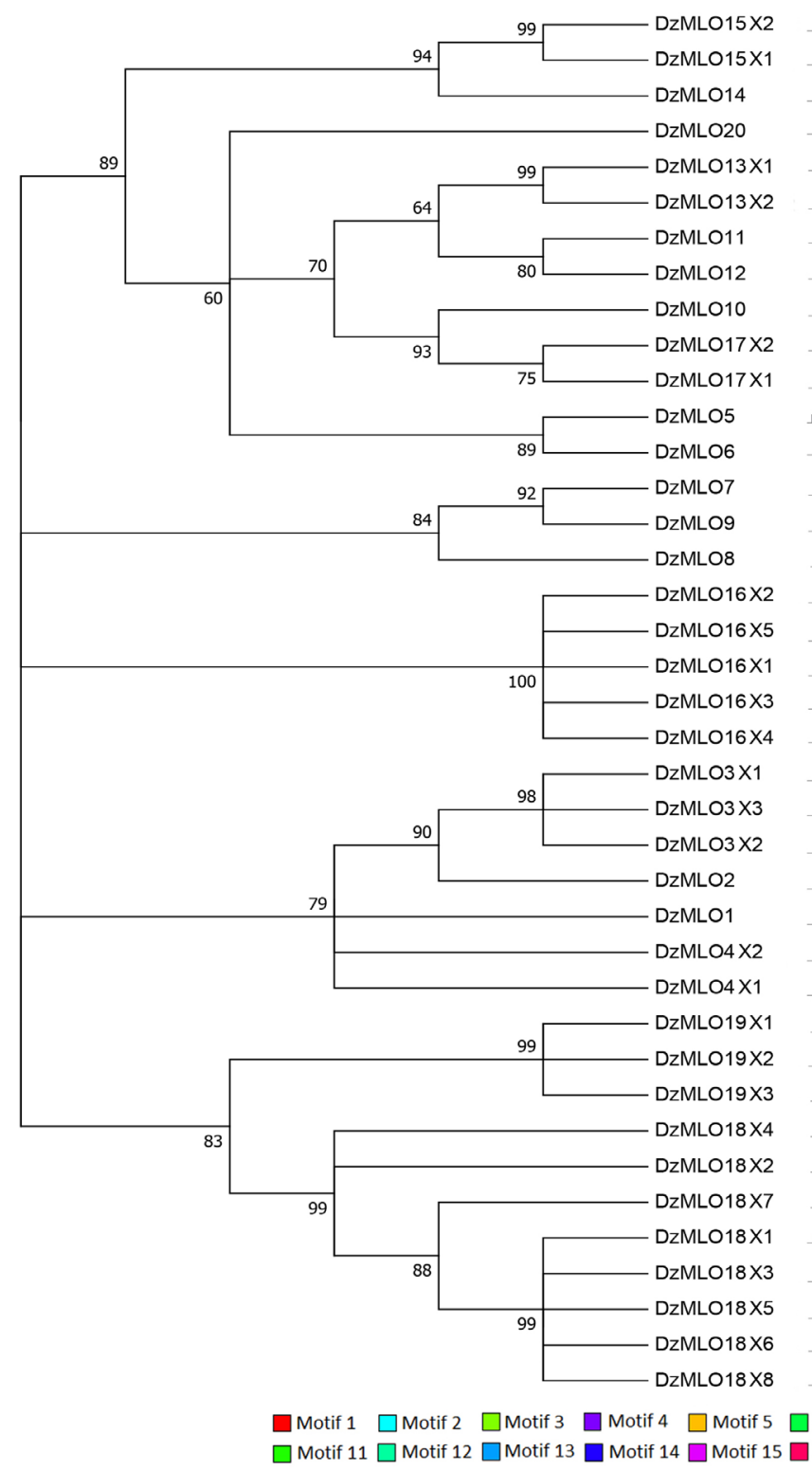

Members of MLO Clade IV and V are suspected to confer susceptibility to PM in monocots and dicots, respectively (Pessina et al. 2016). There are 1 and five members of durian MLO that belong to Clade IV and V, respectively. Those MLOs were clustered together with MLOs that have been linked to susceptibility to PM such as AtMLO02, AtMLO06, and AtMLO12 (Appiano et al. 2015a). It has been shown that Clade IV and $\mathrm{V}$ are complimentary for PM resistance (Appiano et al. 2015a). Interestingly, members of Clade IV and $\mathrm{V}$ have shared motif in C-terminal (Motif 20). This motif is predicted to be associated with signal transduction and response to stimulus (Table 3 ).

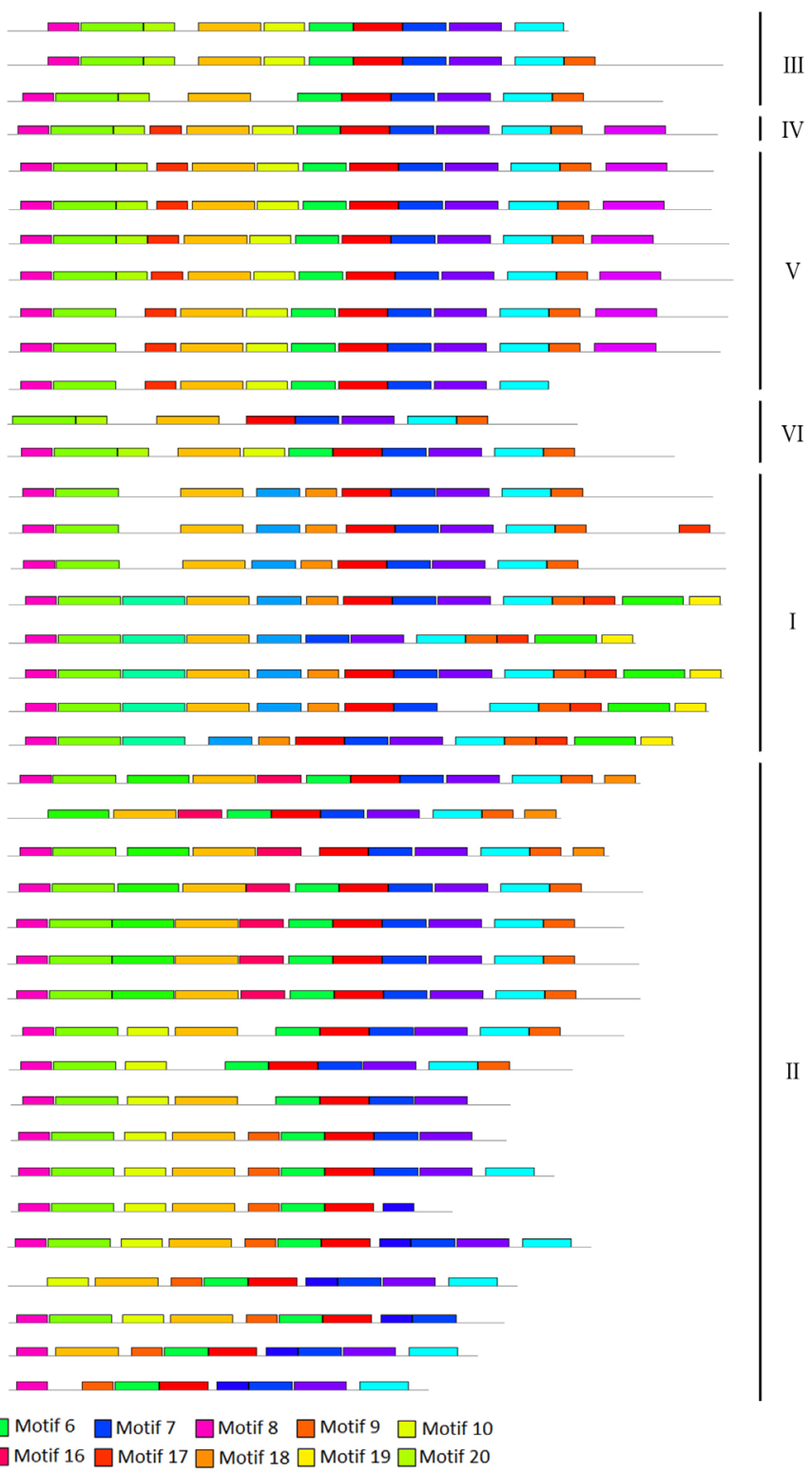

Figure 3. Motifs distribution in DzMLO protein family. Different motifs are colored differently and numbered from 1 to 20 . All motifs were identified using the MEME algorithm. The accompanying dendogram of DzMLO protein was constructed using MEGA 5 (Tamura et al. 2011) 
Table 3. Gene ontology prediction of several protein motifs found in DzMLO Clades IV and V

\begin{tabular}{|c|c|c|c|c|}
\hline Motif & Clade & DzMLO & Location & Top GO Term \\
\hline 6 & II-VI & $1-6,10-15,17-20$ & IC2 & $\begin{array}{l}\text { Localization, Transport (nitrogen compound, ion, organic } \\
\text { substance) }\end{array}$ \\
\hline \multirow[t]{5}{*}{10} & II & $18(X 1-X 5, X 7), 19$ & $\mathrm{EC} 1$ & \multirow{5}{*}{$\begin{array}{l}\text { The nucleic acid metabolic process, transposition, cellular } \\
\text { response to DNA damage }\end{array}$} \\
\hline & III & $(\mathrm{X} 1-\mathrm{X} 2)$ & $\mathrm{IC} 2$ & \\
\hline & IV & 15 & IC2 & \\
\hline & $\mathrm{V}$ & 20 & IC2 & \\
\hline & VI & $\begin{array}{c}10,11,12,13,17 \\
6\end{array}$ & $\mathrm{IC} 2$ & \\
\hline 13 & I & $7,8,9,16(\mathrm{X} 1-\mathrm{X} 2)$ & $\mathrm{IC} 2$ & $\begin{array}{l}\text { Regulation of cellular process (cellular component organization, } \\
\text { organelle organization, cell cycle process) }\end{array}$ \\
\hline \multirow[t]{2}{*}{15} & IV & 20 & $\mathrm{CT}$ & \multirow{2}{*}{$\begin{array}{l}\text { Transposition, DNA integration, cell communication (signal } \\
\text { transduction, response to stimulus) }\end{array}$} \\
\hline & $\mathrm{V}$ & $10,11,12,13,17(\mathrm{X} 1)$ & $\mathrm{CT}$ & \\
\hline \multirow[t]{3}{*}{17} & I & 9,16 & $\mathrm{CT}$ & \multirow{9}{*}{$\begin{array}{l}\text { Regulation of biological process (phosphorylation, intracellular } \\
\text { signal transduction), localisation (macromolecule), transport } \\
\text { (organic substance), regulation of cellular process } \\
\text { Cellular component organisation, regulation of gene expression, } \\
\text { chromatin organisation }\end{array}$} \\
\hline & IV & 20 & $\mathrm{EC} 1$ & \\
\hline & $\mathrm{V}$ & $10,11,12,13,17$ & $\mathrm{EC} 1$ & \\
\hline \multirow[t]{6}{*}{20} & III & 14 & $\mathrm{EC} 1$ & \\
\hline & III & 15 & $\mathrm{EC} 2$ & \\
\hline & IV & 20 & $\mathrm{EC} 1$ & \\
\hline & $\mathrm{V}$ & $11,12,13$ & $\mathrm{EC} 1$ & \\
\hline & VI & 5 & NT & \\
\hline & VI & 6 & $\mathrm{EC} 1$ & \\
\hline
\end{tabular}

Certain motif related to response to the stimulus was also observed by Kusch et al. (2016) in C-terminal of Clade V. As C-terminal plays a role in MLO functionality (Elliott et al. 2005), the motif might explain the overlapping function of Clades IV and V in PM disease. Elliott et al. (2005) also showed the importance of IC2 in MLO proteins. Domain swap between HvMLO and TaMLO-B1 in IC2 and IC2 + CT domain impaired MLO functionality, demonstrated by reduced penetration success of powdery mildew fungus. Presence of Motif 10 in IC2 related to cellular transport and DNA damage response might give further insight into MLO role in PM disease. $\square$

It is interesting to note that our analysis predicted DzMLO17, a member of Clade V, to undergo alternative splicing resulting in a truncated protein. The isoform lacks motifs 9 and 15 that correspond to CaMBD and response to a stimulus, respectively. Apple (Malus domestica) has been found to have a natural truncated MdMLO19 allele that lacks CaMBD. It was hypothesized that such allele would be non-functional and support PM resistance (Pessina et al. 2017). A comparison can be drawn from alternative splicing of plant's resistance $(\mathrm{R})$ proteins that contain $\mathrm{C}$ terminal leucine-rich repeat (LRR) domain. Majority of truncated $\mathrm{R}$ protein isoforms lacking LRR domain are presumably unstable and/or lose the protein's autoinhibition ability (Yang et al. 2014). However, truncated R protein might also confer disease resistance by amplifying plant defense response. This might be achieved through intermolecular interactions between truncated and regular $\mathrm{R}$ proteins to increase active $\mathrm{R}$ protein dimerization. (Yang et al. 2014). Homooligomerisation and C-terminal have both been shown to contribute to AtMLO7 protein activity during pollen tube reception (Jones et al. 2017). Therefore interaction between isoforms to stabilize oligomerization might play a part in MLO activity. However, Pessina et al. (2017) observed that while there were four apple individuals homozygous for MdMLO19 truncated allele that were very resistant to PM, there was a homozygous apple individual that was very susceptible to PM. Therefore mechanism of MLO role in PM susceptibility is still poorly understood. The identification of alternative splicing events in $M L O$ should allow further functional characterization to understand their role in a plant's physiological events (Sablok et al. 2017). $\square$

\section{Expression pattern analysis}

Mining from transcriptomic short reads showed differential expression patterns among DzMLO Clades IV and V (Table 4). DzMLO20, a Clade IV member, was not detected in any tissue sample. DzMLO12 was detected in all tissue samples. DzMLO10 and DzMLO17 were detected in leaf, root, stem, and aril 1. DzMLO13 was only detected in aril 1, while DzMLO11 was only detected in the root. There was no pattern difference between isoforms of DzMLO13 and DzMLO17.

Table 4. $D z M L O$ gene expression pattern

\begin{tabular}{cccccccc}
\hline Clade & DzMLO & Leaf & Root & Stem & Aril 1 & Aril 2 & Aril 3 \\
\hline IV & 20 & - & - & - & - & - & - \\
V & 10 & + & + & + & + & - & - \\
& 11 & - & + & - & - & - & - \\
& 12 & + & + & + & + & + & + \\
& 13 X1 & - & - & - & + & - & - \\
& 13 X2 & - & - & - & + & - & - \\
$17 X 1$ & + & + & + & + & - & - \\
& 17 X2 & + & + & + & + & - & - \\
\hline
\end{tabular}


MLO displays unequal redundancy (Consonni et al. 2006). Presence of DzMLO12 transcript in all tissue samples might indicate its role as major PM MLO. Higher expression in the absence of PM infection has been analyzed in major PM $M L O$ genes such as $A$. thaliana AtMLO2 (Chen et al. 2006), tomato SIMLO1 (Zheng et al. 2016), cucumber CsaMLO8 (Berg et al. 2017), and rice OsMLO3 (Nguyen et al. 2016). Those genes are expressed in leaf, root, and flower. AtMLO2, CsaMLO8, and OsMLO3 are also shown to be expressed in the stem. This differential expression might contribute in unequal redundancy of MLO in PM disease as observed in $A$. thaliana (Consonni et al. 2006), tomato (Zheng et al. 2016), and cucumber (Berg et al. 2017).

In conclusion, we have analyzed 20 putative $D z M L O$ genes encoding 39 putative DzMLO proteins in durian genome. Functional studies, especially on C-terminal and IC2, need to be conducted to elucidate the role of those DzMLOs in PM susceptibility in durian. After characterization of DzMLO as a susceptibility factor for the $\mathrm{PM}$ in durian, genome editing can be conducted to produce PM resistant durian. Nekrasov et al. (2017) have successfully produced transgene-free PM resistant tomato using CRISPR/Cas9 to cause mutation in tomato's primary PM MLO, SlMLO1. This transgene-free mutant is indistinguishable from natural mutant; therefore resistant durian variety will not be categorized nor regulated as genetically modified organism (GMO). The PM resistant durian can be produced and adapted to meet the fruit demands and promote its competitiveness by reducing chemical fungicide input. $\square \square$

\section{REFERENCES}

Appiano M, Catalano D, Martínez MS, Lotti C, Zheng Z, Visser RGF, Ricciardi L, Bai Y, Pavan S. 2015a. Monocot and dicot MLO powdery mildew susceptibility factors are functionally conserved in spite of the evolution of class-specific molecular features. BMC Plant Biol 15: 257. DOI: 10.1186/s12870-015-0639-6.

Appiano M, Pavan S, Catalano D, Zheng Z, Bracuto V, Lotti C, Visser RGF, Ricciardi L, Bai Y. 2015b. Identification of candidate $M L O$ powdery mildew susceptibility genes in cultivated Solanaceae and functional characterization of tobacco NtMLO1. Transgenic Res 24: 847-858.

Acevedo-Garcia J, Kusch S, Panstruga R. 2014. Magical mystery tour: MLO proteins in plant immunity and beyond. New Phytol 204 (2): 273-281.

Australian Quarantine and Inspection Service [AQIS]. 1999. Final import risk analysis on the importation of fresh durian fruit (Durio zibethinus Murray) from the Kingdom of Thailand. Retrieved from http://www.agriculture.gov.au/SiteCollectionDocuments/ba/plant/ung roupeddocs/durianfira.pdf.

Bailey TL, Bodén M, Buske FA, Firth M, Grant CE, Clementi L, Ren J, Li WW, Noble WS. 2009. MEME SUITE: tools for motif discovery and searching. Nucleic Acids Res 37: W202-W208.

Berg JA, Appiano M, Bijsterbosch G, Visser RGF, Schouten HJ, Bai Y. 2017. Functional characterization of cucumber (Cucumis sativus L.) Clade V MLO genes. BMC Plant Biol 17: 80. DOI: 10.1186/s12870017-1029-z.

Black DL. 2003. Mechanisms of alternative pre-messenger RNA splicing. Annu Rev Biochem 72: 291-336.

Boyle EI, Weng S, Gollub J, Jin H, Botstein D, Cherry JM, Sherlock G. 2004. GO: TermFinder-open source software for accessing Gene Ontology information and finding significantly enriched Gene
Ontology terms associated with a list of genes. Bioinformatics 20: 3710-3715. $\square$

Chen Y, Wang Y, Zhang H. 2014. Genome-wide analysis of the mildew resistance locus o $(M L O)$ gene family in tomato (Solanum lycopersicum L.). Plant Omics J 7 (2): 87-93.

Chen Z, Hartmann HA, Wu MJ, Friedman EJ, Chen JG, Pulley M, Schulze-Lefert P, Panstruga R, Jones AM. 2006. Expression analysis of the AtMLO gene family encoding plant-specific seventransmembrane domain proteins. Plant Mol Biol 60: 583-597.

Chen Z, Noir S, Kwaaitaal M, Hartmann HA, Wu MJ, Mudgil Y, Sukumar P, Muday G, Panstruga R, Jones AM. 2009. Two seventransmembrane domain MILDEW RESISTANCE LOCUS O proteins cofunction in Arabidopsis root thigmomorphogenesis. Plant Cell 21 (7): 1972-1991.

Cheng H, Kong W, Hou D, Lv J, Tao X. 2013. Isolation, characterization, and expression analysis of CmMLO2 in muskmelon. Mol Biol Rep 40 (3): 2609-2615

Cheng H, Kun W, Liu D, Su Y, He Q. 2012. Molecular cloning and expression analysis of CmMlo1 in melon. Mol Biol Rep 39 (2): 19031907.

Consonni C, Humphry ME, Hartmann HA, Livaja M, Durner J, Westphal L, Vogel J, Lipka V, Kemmerling B, Schulze-Lefert P, Sommerville SC, Panstruga R. 2006. Conserved requirement for a plant host cell protein in powdery mildew pathogenesis. Nat Genet 38 (6): 716-720.

Deshmukh R, Singh VK, Singh BD. 2017. Mining the Cicer arietinum genome for the mildew locus $O$ (Mlo) gene family and comparative evolutionary analysis of the Mlo genes from Medicago truncatula and some other plant species. J Plant Res 130 (2): 239-253.

Devoto A, Hartmann HA, Piffanelli P, Elliott C, Simmons C, Taramino G, Goh C-S, Cohen FE, Emerson BC, Schulze-Lefert P, Panstruga R. 2003. Molecular phylogeny and evolution of the plant-specific seventransmembrane MLO family. J Mol Evol 56: 77-88.

Edgar, R. 2004. MUSCLE: multiple sequence alignment with high accuracy and high throughput. Nucleic Acids Res 32 (5): 1792-1797.

Elliott C, Müller J, Miklis M, Bhat RA, Schulze-Lefert P, Panstruga R. 2005. Conserved extracellular cysteine residues and cytoplasmic loop-loop interplay are required for functionality of the heptahelical MLO protein. Biochem J 385: 243-254.

Feechan A, Kabbara S, Dry IB. 2011. Mechanisms of powdery mildew resistance in the Vitaceae family. Mol Plant Pathol 12 (3): 263-274.

Grant CE, Bailey TL, Noble WS. 2011. FIMO: Scanning for occurrences of a given motif. Bioinformatics 27 (7): 1017-1018.

Hall B. 2013. Building Phylogenetic Trees from Molecular Data with MEGA. Mol Biol Evol 30 (5): 1229-1235.

Heffer V, Johnson KB, Powelson ML, Shishkoff N. 2006. Identification of Powdery Mildew Fungi anno 2006. The Plant Health Instructor. DOI: 10.1094/PHI-I-2006-0706-01.

Hubert J, Fourrier C, Payen C, Fournié JL, Ioos R. 2012. First report of powdery mildew caused by Podosphaera pannosa on Prunus cerasus in France. Plant Dis 96 (9): 1375-1375.

Jones D, Taylor W, Thornton J. 1992. The rapid generation of mutation data matrices from protein sequences. Bioinformatics 8 (3): 275-282.

Keren H, Lev-Maor G, Ast G. 2010. Alternative splicing and evolution: diversification, exon definition, and function. Nat Rev Genet 11 (5): 345-355. $\square$

Kuhn H, Kwaaitaal M, Kusch S, Acevedo-Garcia J, Wu H, Panstruga R. 2016. Biotrophy at its best: Novel findings and mysteries of the Arabidopsis-Powdery Mildew pathosystem. Arabidopsis Book 14: e0184. DOI: 10.1199/tab.0184.

Kusch S, Pesch L, Pastruga R. 2016. Comprehensive phylogenetic analysis sheds light on the diversity and origin of the MLO family of integral membrane proteins. Genome Biol Evol 8 (3): 878-895.

Li JX, Schieberle P, Steinhaus M. 2012. Characterization of the major odor-active compounds in Thai durian (Durio zibethinus L. 'Monthong') by aroma extract dilution analysis and headspace gas chromatography-olfactometry. J Agric Food Chem 60 (45): 1125311262 .

Liu LP, Qu JW, Yi XQ, Huang HH. 2017. Genome-wide identification, classification and expression analysis of the Mildew Resistance Locus $\mathrm{O}$ (MLO) gene family in sweet orange (Citrus sinensis). Braz Arch Biol Tech 60: e17160474. DOI: 10.1590/1678-4324-2017160474. 
Mohapatra C, Chand R, Singh VK, Singh AK, Kushwaha C. 2016 Identification and characterization of Mlo genes in pea (Pisum sativum L.) vis-à-vis validation of Mlo gene-specific markers. Turkish J Biol 40 (1): 184-195.

Nekrasov V, Wang C, Win J, Lanz C, Weigel D, Kamoun S. 2017. Rapid generation of transgene-free powdery mildew resistant tomato by genome deletion. Sci Rep 7: 482. DOI: 10.1038/s41598-017-00578-X.

Nguyen VNT, Vo KTX, Park H, Joen JS, Jung KH. 2016. A systematic view of the $M L O$ family in rice suggests their novel roles in morphological development, diurnal responses, the light-signaling pathway, and various stress responses. Front Plant Sci 7: 1413. DOI: 10.3389/fpls.2016.01413.

Pessina S, Lenzi L, Perazzolli M, Campa M, Dalla Costa L, Urso S, Vale G, Salamini F, Velasco R, Malnoy M. 2016. Knockdown of MLO genes reduces susceptibility to powdery mildew in grapevine. Hortic Res 3: 16016. DOI: 10.1038/hortres.2016.16.

Pessina S, Palmieri L, Bianco L, Gassmann J, van de Weg E, Visser RGF, Magnago P, Schouten HJ, Bai Y, Velasco R, Malnoy M. 2017. Frequency of a natural truncated allele of MdMLO19 in the germplasm of Malus domestica. Mol Breeding 37: 7. DOI: 10.1007/s11032-016-0610-8.

Qin B, Zheng F, Zhang Y. 2015. Molecular cloning and characterization of a Mlo gene in rubber tree (Hevea brasiliensis). J Plant Physiol 175: 78-85.

Qiu X, Jian H, Wang Q, Tang K, Bao M. 2015. Expression pattern analysis of four Mlo genes from rose. J Am Soc Hortic Sci 140 (4) 333-338.

Rispail N, Rubiales D. 2016. Genome-wide identification and comparison of legume $M L O$ gene family. Sci Rep 6: 32673. DOI: $10.1038 /$ srep32673.

Rubiales D, Fondevilla S, Chen W, Gentzbittel L, Higgins TJV, Castillejo MA, Sing KB, Rispail N. 2015. Achievements and challenges in legume breeding for pest and disease resistance. Crit Rev Plant Sci 34 (1-3): 195-236.

Sablok G, Powell B, Braessler J, Yu F, Min XJ. 2017. Comparative landscape of alternative splicing in fruit plants. Curr Plant Biol 9-10: 29-36.

Schouten HJ, Krauskopf J, Visser RGF, Bai Y. 2014. Identification of candidate genes required for susceptibility to powdery or Downey mildew in cucumber. Euphytica 200 (3): 475-486. $\square$

Siahaan SAS, Hidayat I, Kramadibrata K, Meeboon J, Takamatsu S. 2016. Bauhinia purpurea, Durio zibethinus, and Nephelium lappaceum: additional hosts of the asexual morph of Erysiphe quercicola. Mycoscience 57 (6): 375-383.

Tamura K, Nei M. 1993. Estimation of the number of nucleotide substitutions in the control region of mitochondrial DNA in humans and chimpanzees. Mol Biol Evol 10 (3): 512-526.

Tamura K, Peterson D, Peterson N, Stecher G, Nei M, Kumar S. 2011. MEGA5: Molecular evolutionary genetics analysis using maximum likelihood, evolutionary distance, and maximum parsimony methods. Mol Biol Evol 28 (10): 2731-2739.

Teh BT, Lim K, Yong CH, Ng CCY, Rao SR, Rajasegaran V, Lim WK, Ong CK, Chan K, Cheng VKY, Soh PS, Swarup S, Rozen SG, Nagarajan N, Tan P. 2017. The draft genome of tropical fruit durian (Durio zibethinus). Nat Genet 49 (11): 1633-1641.

Yang S, Tang F, Zhu H. 2014. Alternative splicing in plant immunity. Int J Mol Sci 15: 10424-10445.

Zheng Z, Appiano M, Pavan S, Bracuto V, Ricciardi L, Visser RGF, Wolters AMA, Bai Y. 2016. Genome-wide study of the tomato SIMLO gene family and its functional characterization in response to the powdery mildew fungus Oidium neolycopersici. Front Plant Sci 7: 380. DOI: $10.3389 /$ fpls.2016.00380.

Zhou SJ, Jing Z, Shi JL. 2013. Genome-wide identification, characterization, and expression analysis of the MLO gene family in Cucumis sativus. Genet Mol Res 12 (4): 6565-6578. 